\title{
Screening Extracts of Seven Edible Mushrooms for Reduction of Regeneration Time in the Planarian Dugesia hymanae
}

\author{
Elgin Paul B. Quebral, MD, PhD(c) ${ }^{1,2}$ and Paul Mark B. Medina, $\mathrm{PhD}^{2}$ \\ ${ }^{1}$ College of Medicine, University of the Philippines Manila, Manila, Philippines \\ ${ }^{2}$ Biological Models Laboratory, Department of Biochemistry and Molecular Biology, College of Medicine, University of the Philippines Manila, Manila, Philippines
}

\begin{abstract}
Objective. This study aimed to determine the effect of seven edible mushrooms in the regeneration rate of planarian Dugesia hymanae (D. hymanae).

Methods. The ability of $D$. hymanae to regenerate was used to test extracts of seven mushrooms to reduce regeneration time, using eyespot and tail formations as endpoints. The planarians were amputated and were allowed to heal and regenerate in planarian water (control) and varying concentrations of Crude Ethanolic Extracts (CEE) of the seven edible mushrooms. The CEE with the most significant effect in reducing the regeneration time will be further sub-fractionated into hexane, ethyl acetate, and ethanol solvent extracts.

Results. In untreated planarian water, amputated planarians' eyespot and tail formations took 4.65 (SD 0.34 ) and 4.1 (SD 0.21) days, respectively. The CEE of four mushrooms (Shiitake var Benguet, Tea tree, Shiitake var flower, and Black $\&$ White) significantly reduced the regeneration time, with Shiitake var Benguet extract reducing the regeneration time the most at 2.56 (SD 0.30) days and 2.61 (SD 0.22) days for both eyespot and tail formations $(P<.0001)$ respectively. The solvent extracts of the Shiitake (Benguet variety) did not reduce the planarian regeneration time relative to the control $(P>.05)$.

Conclusion. Lentinula edodes (L. edodes) [Benguet variety CEE] had reduced the regeneration time most significantly for both the eyespot and tail formations compared to the other six tested fungi extracts. The L. edodes (Benguet variety) CEE may contain compounds that can hasten the regeneration of the planarian $D$. hymanae.
\end{abstract}

Keywords: wound healing, regeneration, mushrooms, Dugesia, planarians

\section{INTRODUCTION}

Corresponding author: Paul Mark B. Medina, PhD Department of Biochemistry and Molecular Biology College of Medicine

University of the Philippines Manila

547 Pedro Gil Street Ermita, Manila 1000, Philippines

Email: pbmedina@up.edu.ph
Edible mushrooms are widely consumed, particularly in Asian countries like the Philippines, China, and Japan. ${ }^{1-4}$ Some edible mushrooms had been shown to have pharmaco-medical importance due to their antiinflammatory, antioxidative, immunomodulatory, anti-tumor, and anti-microbial effects. ${ }^{1,3,5,6}$ However, even if the medical significance of mushrooms is extensively documented, natural products from mushrooms are underexplored. ${ }^{4}$ Interestingly, fungal extracts have been shown to enhance wound healing in mammalian models. ${ }^{7-9}$ Finding new treatments that can potentially improve the wound healing rate for patients with wound injury is essential to delimit exacerbation of wound damage.

Wound healing and regeneration are two intimately related processes to repair or replace damaged tissues. ${ }^{10,11}$ Regeneration is simply a more complex form of wound healing. ${ }^{12,13}$ Most wound healing research was done in mammalians, and the investigators want to use a more 
appropriate screening model, the planarian regeneration model.

Planarian is an established model for studies in regeneration and stem cell biology due to their remarkable ability to regenerate because of the presence of the pluripotent stem cells called neoblast. ${ }^{14-19}$ Interestingly, gene expression of pluripotency determinants, epigenetic regulations, and histone modifications are conserved between planarian and human stem cells, and thus planarians are an appropriate model for humans to study wound healing and regeneration..$^{20-22}$

This study aimed to determine the relative performance of the CEE of seven common edible mushrooms on their ability to reduce regeneration time in $D$. bymanae. The topranking mushroom CEE that reduced the regeneration time was identified and was separated using solvents (ethanol, hexane, and ethyl acetate) of different polarities. Each of these solvent extracts was tested in their regeneration and wound healing properties in D. bymanae.

\section{MATERIALS AND METHODS}

\section{Edible Mushrooms}

Seven mushrooms were obtained, identified, and verified to be the following: three Shiitake (Lentinula edodes) varieties (flower, fragrant, and Benguet), Tea Tree (Agrocybe cylindracea), Black and White (Auricularia auricula), White Fungi (Tremella fuciformis), and Black Fungi (Auricularia polytricha) as seen in Figure 1. The identity of the mushrooms used in this study was verified by Dr. Renato G. Reyes, previous director of the Center for Tropical Mushroom Research and Development of the Central Luzon State University, Nueva Ecija, Philippines. The samples were cleaned, dried, and homogenized to prepare a $70 \%$ ethanolic solution for each extract. The ethanolic portion of the extracts was removed by rotary evaporation (Büchi Rotavapor R-200, Sigma-Aldrich, St.Louis, MO, USA), and the remaining aqueous portion was lyophilized using a SpeedVac (Savant DNA Speed $\operatorname{Vac}^{\circledR}$ DNA 110, Thermo Fisher Scientific, Waltman, MA, USA). The lyophilized mushroom CEEs were resuspended at varying concentrations using planarian water. Sub-lethal concentrations of each fungal extract to the planarians were determined using five planarians per concentration. Planarian water contains different salts $(150.07 \mu \mathrm{mol} \mathrm{NaCl}, 6.04 \mu \mathrm{mol} \mathrm{KCl}$, and $100.02 \mu \mathrm{mol}$ $\mathrm{CaCl}_{2}$ ) based on the planarian care instructions of the Levin Lab of Tufts University, Massachusetts, USA.

After testing for the effect of the different mushroom extracts, the CEE with the highest wound healing and regeneration activity was further characterized by extracting the CEE into three solvents (70\% ethanol, 99\% ethyl acetate, and $99 \%$ hexane) of different polarities. A separatory funnel was used to separate the solutions of extracted components from each of the other solvent extracts. The extracting solvents were removed from each of the extracted components by rotary evaporation, and each of the remaining portions was resuspended at varying concentrations using planarian water.

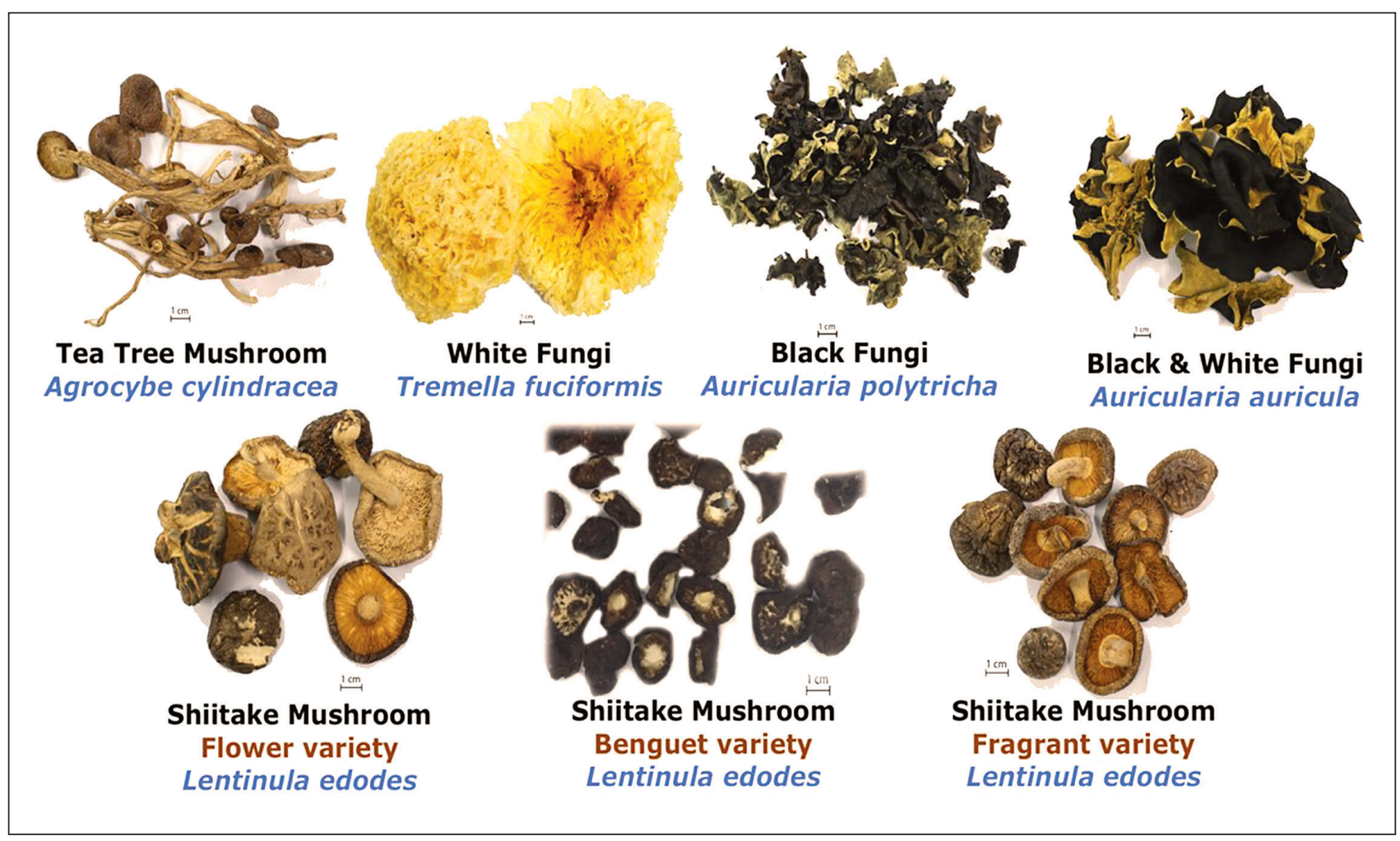

Figure 1. The seven edible fungi were tested for their regeneration properties. The bar scale below each image indicates $1 \mathrm{~cm}$. 


\section{Test Animals}

Planarians (D. hymanae) were collected from a stream in Bucal, Calamba City, Laguna, Philippines $\left(14^{\circ} 11^{\prime} 07.7^{\prime \prime} \mathrm{N}, 121^{\circ} 10^{\prime} 19.7^{\prime \prime} \mathrm{E}\right)$. The identity of the planarians was previously verified by the Laboratory of Molecular Developmental Biology of Kyoto University in Japan and by available scientific literature. ${ }^{23-25}$ All planarians were acclimatized in a temperature-controlled condition $\left(24^{\circ} \mathrm{C}\right)$ for two weeks and were fed with yolk from hard-boiled eggs every day. In each fungal set-up, the collected planarians were distributed into six groups (one control group at $0 \mu \mathrm{g} /$ $\mathrm{mL}$ of the extract and five treatment groups at 5, 50, 100, 250 , and $500 \mu \mathrm{g} / \mathrm{mL}$ of the extract). Each group consisted of 10 biological replicates of the planarians $(n=10)$. The same number of planarians was used for the regeneration assays using the solvent extracts. Overall, 600 planarians were used in the regeneration assays.

\section{Regeneration Assay}

In each concentration of the fungal $\mathrm{CEE}$, ten biological replicates of the planarians $(n=10)$ were transversely cut at the midsection and were exposed to each of the sub-lethal concentrations of each fungus. The planarians were allowed to heal and regenerate in planarian water at a temperaturecontrolled condition $\left(24^{\circ} \mathrm{C}\right)$ and observed every $12-\mathrm{hr}$ until the regeneration endpoint. We used the following regeneration endpoint criteria as follows: (1) appearance of eyespots in the anterior, and (2) appearance of tapered (V-shaped) tail in the posterior. ${ }^{25}$ The fungal CEE that reduced regeneration time of amputated planarians the most was determined (Figure 2). This fungal CEE was subfractionated using hexane, ethyl acetate, and ethanol to make hexane, ethyl acetate, and ethanol solvent extracts of the fungal CEE. These three solvent extracts were also tested for the planarian regeneration assay.

\section{Statistical Analysis}

The mean time for each planarian to form the regeneration endpoints was determined for each concentration of the different fungal extracts. The mean regeneration time for each experimental set-up was compared to the control. The difference was considered significant when the $P<.05$ using the independent t-test of the Open Epi statistical software. ${ }^{26}$

\section{RESULTS}

\section{Shiitake L. edodes (Benguet variety) CEE reduces planarian regeneration time most significantly}

After transverse amputation of the planarians at their midsections, complete regeneration was considered accomplished upon the appearance of eyespots or the formation of V-shaped tails (Figure 2). Among the seven tested fungal CEE (Figures 1, 3, and 4), the Shiitake Lentinula edodes (Benguet variety) reduced the regeneration time of planarians most significantly for both eyespot appearance $(P<.0001)$ and tail formation $(P<.0001)$. The time for eyespot appearance was shortest at $500 \mu \mathrm{g} / \mathrm{mL}$ with a mean regeneration time of 2.56 (SD 0.34) days (Figure 4A). This means the regeneration time point was significantly faster than the regeneration of untreated planarians, which was 4.65 (SD 0.34) days $(P<.0001)$. However, it has to be noted that a significant reduction in the regeneration time of CEE-treated planarians relative to the untreated planarians was already demonstrated starting at $5 \mu \mathrm{g} / \mathrm{mL}$.

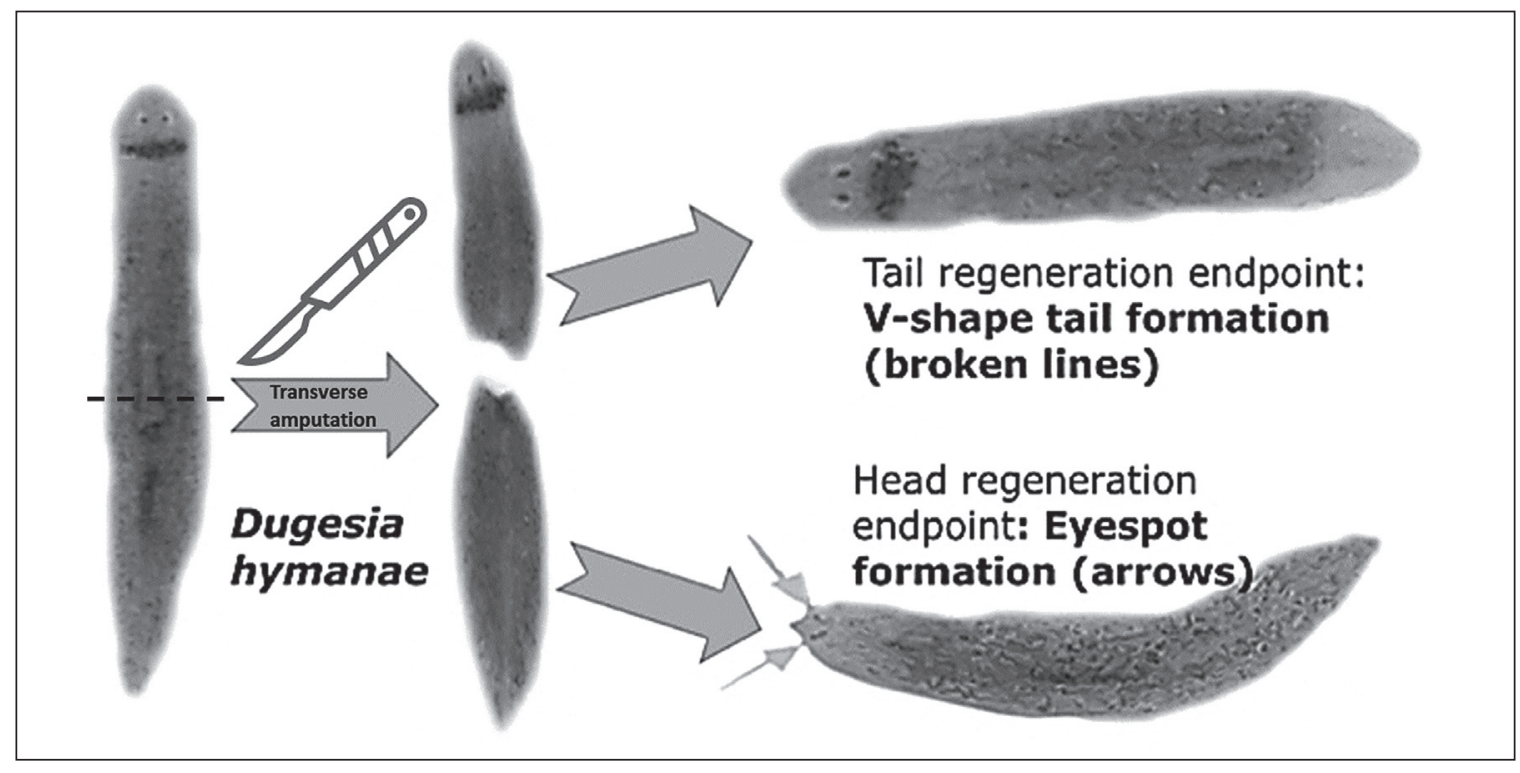

Figure 2. Illustration of the Regeneration Endpoints of Planarians (D. hymanae). After amputation at the midsection, the planarians were exposed to different concentrations of each fungal extract. They were observed to form the regeneration endpoints (i.e., V-shape tail and eyespot formation formations). 


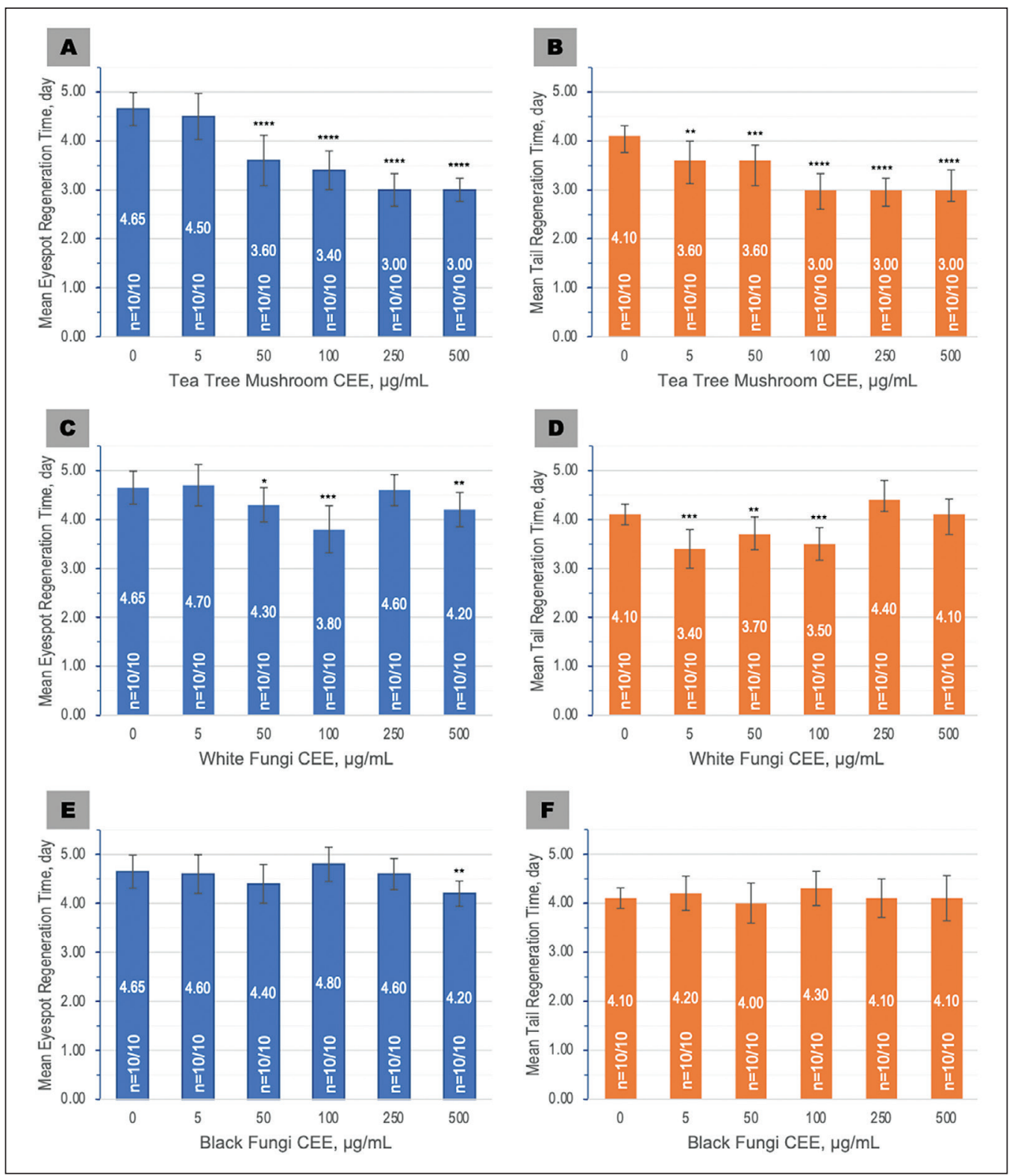

Figure 3. Mean Regeneration Time of D. hymanae Exposed to Different Crude Ethanolic Extracts (CEE) of Edible Mushrooms.

The left column (blue bar graphs) shows the eyespot regeneration data, while the right column (orange bar graphs) shows the tail regeneration data. The number of tested planarians for each set-up is indicated by $n$. The surviving planarians at the experiment's end are the numerator and the total number of tested planarians as the denominator. Error bars indicate the standard deviation of the mean regeneration time. Each extract was compared to the control and significant difference were determined at ${ }^{*} P$-value $<.05$, ${ }^{* *} P$-value $<.01,{ }^{* * *} P$ value $<.001$, and ${ }^{* * * *} P$ value $<.0001$

On the other hand, the shortest time for regenerating the $\mathrm{V}$-shaped tails was observed at 250 and $500 \mu \mathrm{g} / \mathrm{mL}$ of Shiitake Benguet variety CEE, with both concentrations exhibiting a mean regeneration time of 2.61 (SD 0.22) days with $P<.0001$ (Figure 4B). This means the regeneration time point was significantly lower than the regeneration of untreated planarians, which was 4.10 (SD 0.33) days. Similarly, as observed in the eyespot appearance described above, the study showed that the minimum concentration of Shiitake (Benguet variety) CEE for significantly reducing the regeneration of the tail was at $5 \mu \mathrm{g} / \mathrm{mL}$. This concentration is similar to the minimum $\mathrm{CEE}$ concentration at which the regeneration time of the eyespot was reduced. Similarly, both the eyespot and tail regenerations showed a dosedependent reduction in the regeneration time, but they seem to plateau at specific concentrations (Figure 4A-B). 


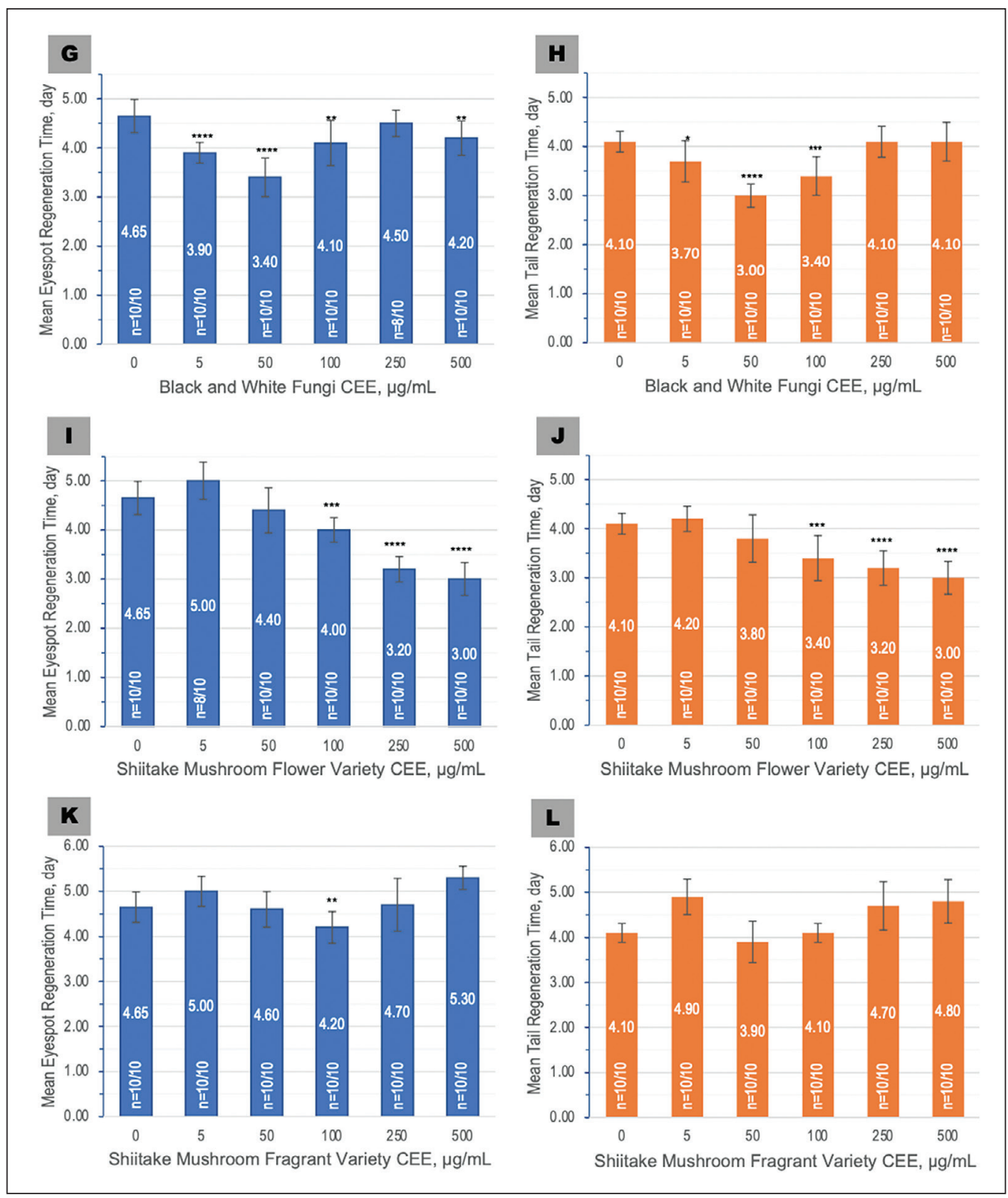

Figure 3. Mean Regeneration Time of D. hymanae Exposed to Different Crude Ethanolic Extracts (CEE) of Edible Mushrooms. (continued)

The left column (blue bar graphs) shows the eyespot regeneration data, while the right column (orange bar graphs) shows the tail regeneration data. The number of tested planarians for each set-up is indicated by $n$. The surviving planarians at the experiment's end are the numerator and the total number of tested planarians as the denominator. Error bars indicate the standard deviation of the mean regeneration time. Each extract was compared to the control and significant difference were determined at ${ }^{*} P$-value $<.05$, ${ }^{* *} P$-value $<.01,{ }^{* * *} P$ value $<.001$, and ${ }^{* * *} P$ value $<.0001$.

\section{Solvent Extracts of Shiitake L. edodes (Benguet variety) did not reduce the regeneration time}

The Shiitake (Benguet variety) CEE reduced the regeneration time of $D$. hymanae most significantly compared to six other mushroom CEEs (Figures 3 and 4). The Shiitake (Benguet variety) CEE was extracted using different solvents - ethanol (aqueous), ethyl acetate, and hexane, further to characterize the regenerative properties of the solvent extracts. The planarian regeneration assays using the solvent extracts of Shiitake (Benguet variety) showed the mean regeneration time was not significantly different from that of the control with a mean eyespot and tail regeneration time of 3.00 (SD 0.27) and 3.15 days (SD 0.34), respectively (Figure $4 \mathrm{C}-\mathrm{F}$ ). 

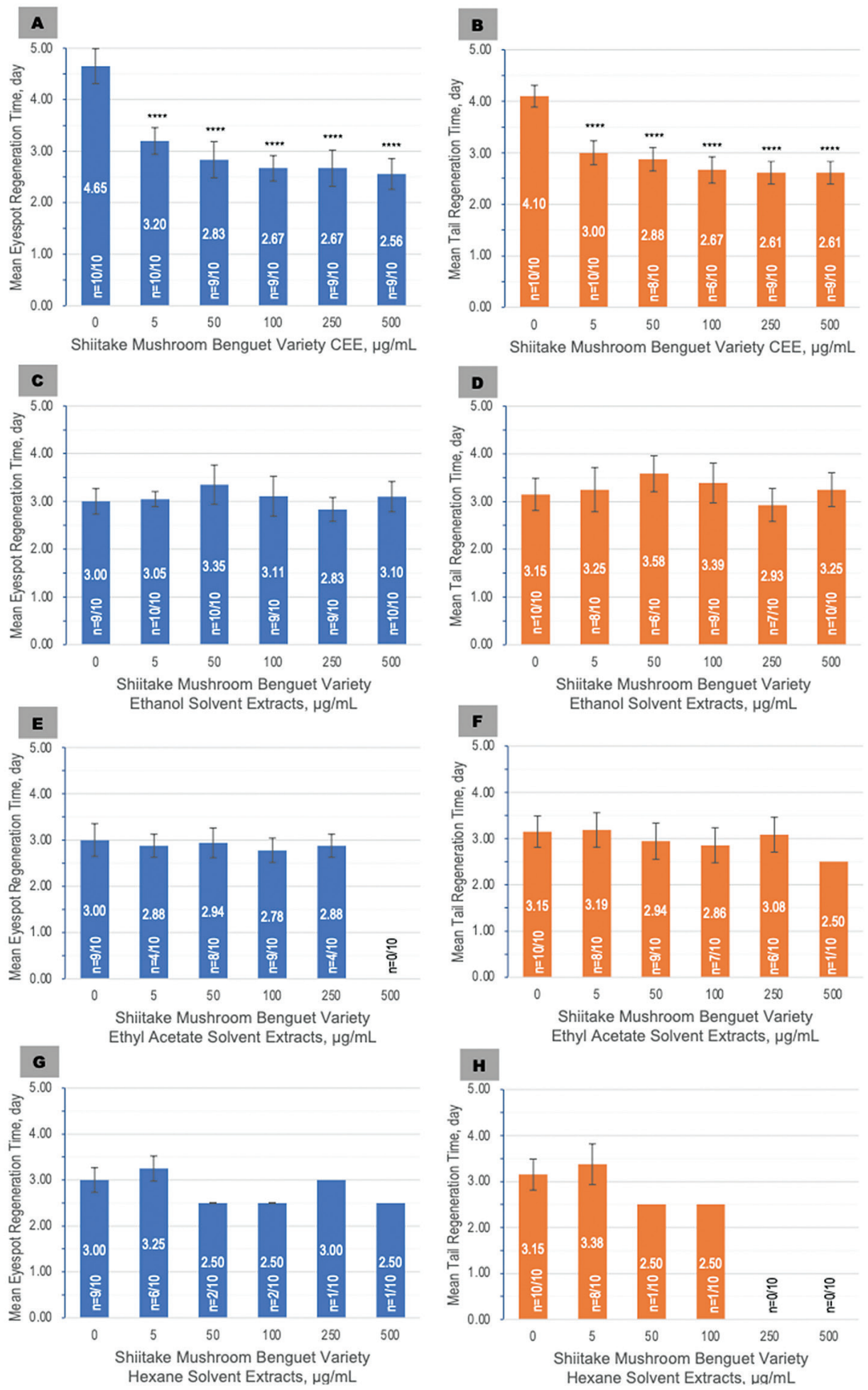

Figure 4. D. hymanae Mean Regeneration Time in the Solvent Extracts (ethyl alcohol, ethyl acetate, hexane) of the Crude Ethanolic Extract of Shiitake Lentinula edodes (Benguet variety).

The left column shows the eyespot regeneration data (blue), while the right column shows the tail regeneration data (orange). The number of tested planarians for each set-up was indicated by $n$. The surviving planarians at the experiment's end are the numerator and the total number of tested planarians as the denominator. Error bars indicate the standard deviation of the mean regeneration time. Abbreviation: EtOH, ethyl alcohol; EtOAc, ethyl acetate. P-value: ${ }^{*} P<.05,{ }^{* *} P<.01,{ }^{* * *} P<.001,{ }^{* * *} P$ value $<.0001$. 


\section{DISCUSSION}

\section{Relationship of Planarian Regeneration and the Concentration of L. edodes (Benguet) CEE}

This is an exploratory type of research of discovering potential new sources of regenerative compounds for speeding up or decreasing the time for wound healing. Among the tested fungal CEEs in this study, the Shiitake (Benguet variety) showed the most significant reduction in regeneration time, which translates to faster wound healing and regeneration rates (Figures 3 and 4). All Shiitake (Benguet variety) CEE concentrations showed a remarkable increase $(P<.0001)$ in the speed of eyespot and tail regenerations compared to the negative control. Figures $4 \mathrm{~A}$ and $4 \mathrm{~B}$ also show that there seemed to be a dose-dependent reduction of regeneration time for both the eyespot and tail regeneration assays. To determine whether there was a dosedependent reduction of regeneration time, further statistical comparisons were made amongst the significant $\mathrm{CEE}$ concentrations.

In the eyespot regeneration assay, statistical analysis showed that there was no significant difference between the $50,100,250$, and $500 \mu \mathrm{g} / \mathrm{mL}$, but when these higher concentrations were compared to the $5 \mu \mathrm{g} / \mathrm{mL}$, significant differences were noted at $P=.0177, P=.0003, P=.0003$ and $P=.0001$ respectively. Thus, this suggests that the minimum concentration of Shiitake (Benguet variety) CEE for significantly reducing the regeneration of eyespots was at $5 \mu \mathrm{g} / \mathrm{mL}$ and may begin to plateau at $50 \mu \mathrm{g} / \mathrm{mL}$. The same statistical comparison was also made on the concentrations that significantly reduced the tail regeneration time. Results showed that comparing the tail regeneration rates of planarians exposed to the $5 \mu \mathrm{g} / \mathrm{mL}$; the $50 \mu \mathrm{g} / \mathrm{mL}$ $(P=.2954)$ was not significantly faster. In contrast, the 100 , 250 , and $500 \mu \mathrm{g} / \mathrm{mL}$ were significantly faster in increasing the speed of tail regeneration with $P=.0202, P=.0017$, and $P=.0017$, respectively. Further analysis also revealed that tail regeneration at the $250 \mu \mathrm{g} / \mathrm{mL}(P=.0264)$ and $500 \mu \mathrm{g} / \mathrm{mL}$ $(P=.0264)$ was significantly faster compared with the $50 \mu \mathrm{g} /$ $\mathrm{mL}$ but not with the $100 \mu \mathrm{g} / \mathrm{mL}(P=.6371)$. Thus, this suggests that the minimum concentration of Shiitake (Benguet variety) $\mathrm{CEE}$ for significantly reducing the regeneration of tails was at $5 \mu \mathrm{g} / \mathrm{mL}$ and may begin to plateau at $100 \mu \mathrm{g} / \mathrm{mL}$.

These observed effects may then provide a possible optimal range of the Shiitake (Benguet) CEE concentrations to speed planarian regeneration. Based on the study results, the tested Shiitake (Benguet variety) CEE concentrations hasten the regenerate rate of $D$. hymanae starting at $5 \mathrm{ug} /$ $\mathrm{mL}$ and even significantly faster at higher concentrations. Based on published literature, no data explained why there were observed differences in the L. edodes CEE concentration and the speed of planarian regeneration. We may speculate that, like any other intervention or exposure, the effect of the tested extract will eventually reach its maximum concentration where it can exert its optimal effect. Beyond this optimal range of concentrations, the result of the extract on the planarian regeneration rate may be saturated already. Increasing the concentration may not provide further regenerative effects and may potentially be toxic to the tested animals. As demonstrated by our study, both the eyespot and tail regeneration rates seemed to plateau at a specific concentration as there were no significant differences among the top four $(50,100,250$, and $500 \mu \mathrm{g} / \mathrm{mL})$ and top three $(100,250$ and $500 \mu \mathrm{g} / \mathrm{mL})$ concentrations for the eyespot and tail regeneration assays respectively. Toxicity was not observed in this extract because the concentrations tested were supposedly sub-lethal to the planarians. We did sub-lethal concentration assays to extrapolate proper $\mathrm{CEE}$ concentrations of each extract.

\section{Comparison of the effect of the Shiitake (Benguet variety) on the regeneration of planarian eyespots and tails}

This study showed that both planarian eyespot and tail regenerations exhibited a similar minimum concentration (i.e., $5 \mu \mathrm{g} / \mathrm{mL}$ ) of $L$. edodes CEE, which significantly sped up the regeneration time. All the tested L. edodes CEE concentrations showed a remarkable increase in regenerate rates $(P<.0001)$ as discussed above relative to the negative control. It was also observed that the L. edodes Benguet CEE seemed to reach its estimated maximal effect on the eyespot and tail regeneration times starting at 50 and $100 \mu \mathrm{g} / \mathrm{mL}$, respectively. Based on these results, we may infer that the extract could have differential effects on the eyespot and the tail regeneration processes.

These data suggest that eyespot regeneration requires a lesser concentration of the Shiitake (Benguet) CEE to reach its potential optimal regenerative effect. Since both eyespot and tail regeneration assays showed significant regeneration activities starting at $5 \mu \mathrm{g} / \mathrm{mL}$, it can be inferred that the approximate ranges of the lower limit of the regenerative activities of the $L$. edodes Benguet variety are $5-50 \mu \mathrm{g} / \mathrm{mL}$ for the eyespot regeneration and $5-100 \mu \mathrm{g} / \mathrm{mL}$ for the tail regeneration set-up. Above the respective concentrations, there was no further significant increase in the speed of planarian regeneration as described above. Furthermore, these data also provide us insight into how the $L$. edodes CEE may exert more effect/s on the eyespot regeneration than tail regeneration because eyespot regeneration only required a lower concentration for the amputated planarians to reach the optimal eyespot regenerative effect. Hence, the study showed a more potent effect in increasing eyespot regeneration speed than tail regeneration. To our knowledge, this is the first time that $L$. edodes CEE demonstrated regenerative properties in $D$. bymanae, which was more apparent in speeding up eyespot regeneration compared to tail regeneration. Furthermore, no published literature readily compared the speeds of eyespot versus tail regenerations. 


\section{Basics of planarian regeneration biology}

The regenerative ability of planarians can be explained by abundant pluripotent stem cells called the neoblast. ${ }^{25-29}$ Neoblasts, particularly clonogenic or cNeoblasts, can develop into all adult planarian cell types, which is the functional definition of pluripotency. ${ }^{30}$ In fact, neoblasts are the only source of new cells in planarians, and depletion of neoblasts by irradiation blocks regeneration completely. ${ }^{16,31,32}$ Any wounding event will activate the neoblast proliferation, particularly at the wound site called a blastema. ${ }^{33}$ In our regeneration study, we observed blastema formation and rapid migration of the neoblast near the wound site after transverse amputation.

There are cellular and molecular differences in how the planarian maintains the integrity of its eyespot and tail regeneration processes. The leading proposed mechanism as to how neoblasts are regulated to regenerate the anterior and posterior portions of planarians is through the Wnt pathway. The conserved Wnt signaling was shown to promote tail regeneration processes, such that inhibition of this pathway will transform the existing tail into a head or reprogram a tail blastema into head development in a regenerating planarian. ${ }^{34-36}$ The opposite phenotype has been observed when the Wnt signaling pathway was activated. ${ }^{34,35,37}$ In our study, since there was a more potent effect in increasing the speed of eyespot regeneration, we may speculate that the L. edodes Benguet CEE may potentially promote the inhibition of the Wnt pathway. However, further studies should be done to validate this hypothesis.

\section{Anti-oxidants in L. edodes (Benguet variety) may scavenge wound-induced Reactive Oxygen Species (ROS), promoting faster regeneration}

It has been illustrated that there is an active cell division at the wound site of the planarians after any injury because the cNeoblasts will try to replace or repair the missing structures. ${ }^{25,27-29}$ With an increased rate of cell division, there is also an increased amount of reactive oxygen species (ROS) that may inhibit the wound healing and regeneration process. ${ }^{38-41}$ Hence, the presence of an antioxidant compound, which can scavenge these ROS, may translate to faster wound healing and regeneration, which were observed mainly in $L$. edodes (Benguet variety) CEE. ${ }^{40-42}$

Some studies have shown that a similar ethanolic extract of $L$. edodes contain the following anti-oxidative compounds: phenols $(25.5 \mathrm{ug} / \mathrm{mg})$, ascorbic acid $(1.9 \mathrm{ug} / \mathrm{mg})$, flavonoids (2 ug/mg), beta-carotene (0.015 ug/mg), lycopene (0.01 $\mathrm{ug} / \mathrm{mg}$ ). The phenols and flavonoids were demonstrated to have good antioxidant properties and free scavenging power through different in vitro anti-oxidant assays like the DPPH (2,2-diphenyl-1-picrylhydrazyls) radical scavenging assay, reducing power assay, and superoxide radical scavenging assay. ${ }^{43-45}$ Although these antioxidant capacity assays were not done in our study, it can be suggested that these similar compounds may be responsible for the observed increased regeneration activity in the test animals by preventing regenerating planarian cells from further oxidative stress. We may need further studies to confirm whether these metabolites in $L$. edodes are responsible for increasing the regeneration rates in planarians.

It has also been demonstrated that wound-induced ROS in planarians acts as upstream regulators of tissue regeneration. ${ }^{46}$ Interestingly, it has been suggested that early inhibition of ROS burst may impede the regeneration process, which is indirectly in contrast with the results of our study. ${ }^{47}$ However, it should be noted that the temporal effect of ROS scavengers and their molecular effects in planarian regeneration is not yet fully elucidated. ${ }^{46-47}$ Furthermore, there are no published studies yet on comparing the temporal effect of anti-oxidants, that is, comparing early versus late inhibition of the ROS oxidative bursts in planarian woundinduced ROS. Although more studies need to be done, it can be inferred that the active compounds found in the $L$. edodes extract in our study may exert their effect in the later stage of planarian wound-induced ROS because of the fungi-planarian regeneration assay results showed that there were increased regeneration rates. These data may provide further studies in the timing (early versus late) of exposure to extracts, other interventions or both, in other wound repair and regeneration models.

\section{L. edodes (Benguet variety) Solvent Extracts and planarian regeneration}

To characterize the possible active metabolites in $L$. edodes CEE further, the mushroom extract was further subjected to separation through solvent extraction using solvents of decreasing polarity - ethanol, ethyl acetate, and hexane. Results showed that all the solvent extracts did not significantly reduce the regeneration time of the planarians $(P>.05)$. It was also observed that not all planarians survived, particularly in the highly non-polar solvent extracts (Figure 4E-H). However, the number of planarian deaths was not correlated to the concentration of the ethanol and ethyl acetate solvent extracts. On the other hand, more planarian deaths were noted at the higher concentrations of the hexane solvent extracts,

The differential response of the planarians to the environment they are exposed to, like the different types of solvent extracts, may be attributed to the polarity of the solvents used. In the more polar solvent extracts like ethanol and ethyl acetate, some planarians could tolerate the concentrations they were exposed to. Although some planarians in these solvent extracts regenerated, some planarians died. Meanwhile, the hexane solvent extracts' highly non-polar or hydrophobic properties may explain higher deaths observed in such types of solvent extracts. The highly non-polar property of the hexane molecules can readily interfere with the wound repair processes of the newly exposed planarian wound. Since the nature of the regeneration assay is to amputate the planarians and expose them to the extracts transversely, 
the fragile wound sites are readily exposed to the extracts. These non-polar hexane molecules can then solubilize and easily damage the compromised hydrophobic lipid bilayer of the planarian cell membrane. Consequently, normal wound repair and regeneration will be impaired, and in the worstcase scenario, these planarians may die.

In the solvent extracts set-up of the eyespot regeneration assay, one planarian died at zero concentration. Nonetheless, the surviving nine planarians regenerated completely with no defects. There is always a risk of an animal dying from unknown causes in any animal study, which may also occur even in the control group. All planarians were acclimatized to our experimental conditions for at least two weeks before proceeding with the regeneration assays. Also, healthy planarians were randomly distributed across the different extract types and concentrations. During the experiments, all possible variables were controlled except for the parameter of interest, which is the exposure of the planarians to the different extract types and concentrations. During the execution of the regeneration assays, careful handling of the tested animals was done to avoid unnecessary stress to the planarians.

\section{CONCLUSION}

Shiitake L. edodes (Benguet variety) CEE had reduced the regeneration time most significantly for both anterior and posterior portions compared to the other six tested fungi extracts. All tested concentrations of the L. edodes CEE significantly reduced the regeneration time for both the eyespot and tail regeneration assays. The minimum concentration for considerably reducing the regeneration of the eyespot and tails was both at $5 \mu \mathrm{g} / \mathrm{mL}$ and may begin to plateau at 50 and $100 \mu \mathrm{g} / \mathrm{mL}$, respectively. The ethanol, ethyl acetate, and hexane solvent extracts of the Shiitake Benguet CEE did not reduce the regeneration time of the tested animals. There was no correlation between the concentration of the more polar solvent extracts (ethanol and ethyl acetate) and the observed deaths in the planarians. Meanwhile, there were more planarian deaths in the higher concentrations compared to the lower concentrations of the non-polar hexane solvent extracts.

Initial findings of the study showed the potential of Shiitake (Benguet variety) in reducing the regeneration time of $D$. hymanae. This may justify further investigation, like the characterization of the active metabolite. It is recommended to use more advanced purification techniques such as highperformance liquid chromatography (HPLC). A higher resolution of separation of each fraction of interest will be tested for wound healing and regeneration activities. The range of concentrations at which this extract reduced the regeneration time in planarians can lead to future studies that seek to identify the optimal concentrations. It is also interesting to determine what molecular and cellular pathways are affected by the tested extract and how they relate to the observed differences in the eyespot and tail regeneration times. It is also recommended to explore the other tested mushroom extracts, which showed a significant reduction in regeneration time. Lastly, it is prudent to test these extracts onto a mammalian model (e.g., mice) and eventually humans.

\section{Acknowledgments}

The authors would like to thank the Philippine Council for Health Research and Development (PCHRD) of the Department of Science and Technology (DOST) for providing the research fund through the Accelerated Science and Technology Human Resources Development Program (ASTHRDP) grant for MD-PhD in Molecular Medicine scholars. The authors would also like to express their gratitude to the Department of Biochemistry and Molecular Biology, College of Medicine, University of the Philippines Manila (UPM) for using laboratory equipment and some reagents.

The investigators also wanted to thank Dr. Antoinette Emas, Dr. Jayeanne Bihag, and Ms. Johneth Guzman of the BS Biology program of the University of the Philippines Baguio for their assistance in optimizing the planarian culture conditions. The authors would also like to express their sincerest gratitude to Dr. Daniel Ileto, Mr. Kevin Rae Ngo, and Mr. Joshua Elijah Lanzon of the University of Santo Tomas's BS Biochemistry program in Manila help in the maintenance of the planarian cultures. Furthermore, the authors appreciate Dr. Louise Ruth Paras, Ms. Jian Kristin Sarsagat, and Mr. Jerboe Ocampo of the BS Biochemistry program of UPM for their assistance in the data collection. We also acknowledged the help of Dr. Ben Anthony Lopez for helping in the processing of mushroom extracts and editing the mushroom images.

We would also like to thank Dr. Kiyokazu Agata of Kyoto University in Japan for sharing his knowledge about planarians, Dr. Renato Reyes of the Central Luzon State University in Nueva Ecija for identifying the scientific names of the edible mushrooms, Dr. Michael Levin of Tufts University in the US for providing the formulation of the planarian water, Ms. Franziska Rabert of the Max Planck Institute for Molecular Biomedicine in Germany, and Dr. Nestor Oviedo of the University of California Merced in the US, for providing the initial batch of planarians.

\section{Statement of Authorship}

Both authors have substantial contributions to the conception and design of the work; or the acquisition, analysis or interpretation of date for the work; and drafting the work or revising it critically for important intellectual content; and final approval of the version to be published; and agreement to be accountable for all aspect of the work in ensuring that the questions related to the accuracy or integrity of any part of the work are appropriately investigated and resolved. 


\section{Author Disclosure}

Both authors declared no conflicts of interest.

\section{Funding Source}

The study was funded by the Philippine Council for Health Research and Development (PCHRD) of the Department of Science and Technology (DOST).

\section{REFERENCES}

1. Muszyńska B, Grzywacz-Kisielewska A, Kała K, Gdula-Argasińska J. Anti-inflammatory Properties of Edible Mushrooms: A Review. Food Chem. 2018 Mar 15;243:373-381. doi: 10.1016/j. foodchem.2017.09.149. Epub 2017 Sep 30. PMID: 29146352.

2. Jayachandran M,Xiao J, Xu B. A Critical Review on Health Promoting Benefits of Edible Mushrooms through Gut Microbiota. Int J Mol Sci. 2017 Sep 8;18(9):1934. doi: 10.3390/ijms18091934. PMID: 28885559 ; PMCID: PMC5618583.

3. Thu ZM, Myo KK, Aung HT, Clericuzio M, Armijos C, Vidari G. Bioactive Phytochemical Constituents of Wild Edible Mushrooms from Southeast Asia. Molecules. 2020 Apr 23;25(8):1972. doi: 10.3390/molecules25081972. PMID: 32340227; PMCID: PMC7221775.

4. Dai X, Stanilka JM, Rowe CA, Esteves EA, Nieves C Jr, Spaiser SJ, Christman MC, Langkamp-Henken B, Percival SS. Consuming Lentinula Edodes (Shiitake) Mushrooms Daily Improves Human Immunity: A Randomized Dietary Intervention in Healthy Young Adults. J Am Coll Nutr. 2015;34(6):478-87. doi: 10.1080/07315724.2014.950391. Epub 2015 Apr 11. PMID: 25866155.

5. Zhao S, Gao Q, Rong C, Wang S, Zhao Z, Liu Y, Xu J. Immunomodulatory Effects of Edible and Medicinal Mushrooms and Their Bioactive Immunoregulatory Products. J Fungi (Basel). 2020 Nov 8;6(4):269. doi: 10.3390/jof6040269. PMID: 33171663; PMCID: PMC7712035.

6. Xu T, Beelman RB, Lambert JD. The Cancer Preventive Effects of Edible Mushrooms. Anticancer Agents Med Chem. 2012 Dec;12(10): 1255-63. doi: 10.2174/187152012803833017. PMID: 22583406.

7. Abdulla MA, Fard AA, Sabaratnam V, Wong KH, Kuppusamy UR, Abdullah N, Ismail S. Potential Activity of Aqueous Extract of Culinary-medicinal Lion's Mane Mushroom, Hericium erinaceus (Bull.: Fr.) Pers. (Aphyllophoromycetideae) in Accelerating Wound Healing in Rats. Int J Med Mushrooms. 2011;13(1):33-9. doi: 10.1615/ intjmedmushr.v13.i1.50. PMID: 22135902.

8. Nasiry D, Khalatbary AR, Ebrahimzadeh MA. Anti-Inflammatory and Wound-Healing Potential of Golden Chanterelle Mushroom, Cantharellus Cibarius (Agaricomycetes). Int J Med Mushrooms. 2017;19(10):893-903. doi: 10.1615/IntJMedMushrooms.2017024674. PMID: 29256843.

9. Khamlue R, Naksupan N, Ounaroon A, Saelim N. Skin Wound Healing Promoting Effect of Polysaccharides Extracts from Tremella fuciformis and Auricularia auricula on the Ex-vivo Porcine Skin Wound Healing Model. IPCBEE, 43 (2012): 20. DOI: 10.7763/ IPCBEE. 2012. V43. 20

10. Murawala P, Tanaka EM, Currie JD. Regeneration: The Ultimate Example of Wound Healing. Semin Cell Dev Biol. 2012 Dec;23(9): 954-62. doi: 10.1016/j.semcdb.2012.09.013. Epub 2012 Oct 8. PMID: 23059793.

11. Reinke JM, Sorg H. Wound Repair and Regeneration. Eur Surg Res. 2012;49(1):35-43. doi: 10.1159/000339613. Epub 2012 Jul 11. PMID: 22797712.

12. EuroStemCell. Regeneration: what does it mean and how does it work? [Internet]. 2021 [cited 2021 Jan 12]. Available from https:// www.eurostemcell.org/regeneration-what-does-it-mean-and-howdoes-it-work
13. Wong VW, Gurtner GC, Longaker MT. Wound Healing: A Paradigm for Regeneration. Mayo Clin Proc. 2013 Sep;88(9):1022-31. doi: 10.1016/j.mayocp.2013.04.012. PMID: 24001495.

14. Gentile L, Cebrià F, Bartscherer K. The Planarian Flatworm: An In Vivo Model for Stem Cell Biology and Nervous System Regeneration. Dis Model Mech. 2011 Jan;4(1):12-9. doi: 10.1242/dmm.006692. Epub 2010 Dec 6. PMID: 21135057; PMCID: PMC3014342.

15. Ivankovic M, Haneckova R, Thommen A, Grohme MA, Vila-Farré M, Werner S, Rink JC. Model Systems for Regeneration: Planarians. Development. 2019 Sep 11;146(17):dev167684. doi: 10.1242/dev. 167684. PMID: 31511248.

16. Rink JC. Stem Cell Systems and Regeneration in Planaria. Dev Genes Evol. 2013 Mar;223(1-2):67-84. doi: 10.1007/s00427-012-0426-4. Epub 2012 Nov 9. PMID: 23138344; PMCID: PMC3552358.

17. Pagán OR. Planaria: An Animal Model that Integrates Development, Regeneration and Pharmacology. Int J Dev Biol. 2017;61(8-9): 519-529. doi: 10.1387/ijdb.160328op. PMID: 29139537.

18. Oviedo NJ, Nicolas CL, Adams DS, Levin M. Planarians: A Versatile and Powerful Model System for Molecular Studies of Regeneration, Adult Stem Cell Regulation, Aging, and Behavior. CSH Protoc. 2008 Oct 1;2008:pdb.emo101. doi: 10.1101/pdb.emo101. PMID: 21356684.

19. Mihaylova Y, Abnave P, Kao D, Hughes S, Lai A, Jaber-Hijazi F, Kosaka N, Aboobaker AA. Conservation of Epigenetic Regulation by the MLL3/4 Tumour Suppressor in Planarian Pluripotent Stem Cells. Nat Commun. 2018 Sep 7;9(1):3633. doi: 10.1038/s41467-01806092-6. PMID: 30194301; PMCID: PMC6128892.

20. Onal P, Grün D, Adamidi C, Rybak A, Solana J, Mastrobuoni G, Wang Y, Rahn HP, Chen W, Kempa S, Ziebold U, Rajewsky $\mathrm{N}$. Gene Expression of Pluripotency Determinants is Conserved between Mammalian and Planarian Stem Cells. EMBO J. 2012 Jun 13;31(12):2755-69. doi: 10.1038/emboj.2012.110. Epub 2012 Apr 27. PMID: 22543868; PMCID: PMC3380209.

21. Dattani A, Kao D, Mihaylova Y, Abnave P, Hughes S, Lai A, Sahu S, Aboobaker AA. Epigenetic Analyses of Planarian Stem Cells Demonstrate Conservation of Bivalent Histone Modifications in Animal Stem Cells. Genome Res. 2018 Oct;28(10):1543-1554. doi: 10.1101/gr.239848.118. Epub 2018 Aug 24. PMID: 30143598; PMCID: PMC6169894.

22. Mihaylova Y, Abnave P, Kao D, Hughes S, Lai A, Jaber-Hijazi F, Kosaka N, Aboobaker AA. Conservation of Epigenetic Regulation by the MLL3/4 Tumour Suppressor in Planarian Pluripotent Stem Cells. Nat Commun. 2018 Sep 7;9(1):3633. doi: 10.1038/s41467-01806092-6. PMID: 30194301; PMCID: PMC6128892.

23. Integrated Taxonomic Information System. Dugesia hymanae Taxonomic Serial Number 1039667 [Internet]. 2021 [cited 2021 Jan 14]. Available from: https://www.itis.gov/servlet/SingleRpt/ SingleRpt?search_topic $=$ TSN\&search_value $=1039667 \&$ print version=SCR\&source=from_print\#null

24. Sivickis, PB. The Fresh Water Planarians of the Philippines. Trans Amer Micros Soc. 1928; 47: 356-65.

25. Quebral EPB, Medina PMB. Crude Anthocyanin Extract (CAE) From Ballatinao Black Rice Hastens Regeneration In Dugesia hymanae. J Pharm Biomed Sci. 2015; 05(02): 147-53.

26. Soe MM, Sullivan K, Dean AG. OpenEpi: Open Source Epidemiologic Statistics for Public Health Version 3.01. Two-sample independent t-Test OpenEpi: Open Source Epidemiologic Statistics for Public Health Version 3.01 [Internet]. [cited 2021 Jan 15]. Available from: https://www.openepi.com/Mean/t_testMean.htm.

27. Lange CS. A Quantitative Study of the Number and Distribution of Neoblasts in Dugesia Lugubris (Planaria) with Reference to Size and Ploidy. J Embryol Exp Morphol. 1967 Oct;18(2):199-213. PMID: 6059963.

28. Wenemoser D, Lapan SW, Wilkinson AW, Bell GW, Reddien PW. A Molecular Wound Response Program Associated with Regeneration Initiation in Planarians. Genes Dev. 2012 May 1;26(9):988-1002. doi: 10.1101/gad.187377.112. PMID: 22549959; PMCID: PMC3347795.

29. Reddien PW. The Cellular and Molecular Basis for Planarian Regeneration. Cell. 2018 Oct 4;175(2):327-45. doi: 10.1016/j.cell. 2018.09.021. PMID: 30290140; PMCID: PMC7706840. 
30. Ivankovic M, Haneckova R, Thommen A, Grohme MA, Vila-Farré M, Werner S, Rink JC. Model Systems for Regeneration: Planarians. Development. 2019 Sep 11;146(17):dev167684. doi: 10.1242/dev. 167684. PMID: 31511248.

31. Baguna J. The Planarian Neoblast: the Rambling History of Its Origin and Some Current Black Boxes. Int J Dev Biol. 2012; 56:19-37. doi: 10.1387/ijdb.113463jb

32. Tanaka EM, Reddien PW. The Cellular Basis for Animal Regeneration. Dev Cell. 2011; 21(1): 172-85. https://doi.org/10.1016/j. devcel.2011.06.016.

33. Wenemoser D, Reddien PW. Planarian Regeneration Involves Distinct Stem Cell Responses to Wounds and Tissue Absence. Dev Biol. 2010; 344, 979-91. https://doi.org/10.1016/j.ydbio.2010.06.017

34. Gurley KA, Rink JC, Sánchez Alvarado A. $\beta$-catenin Defines Head versus Tail Identity during Planarian Regeneration and Homeostasis. Science. 2008; 319, 323-7. https://doi.org/10.1126/science.1150029

35. Iglesias M, Gomez-Skarmeta JL, Saló E, Adell T. Silencing of Smedbetacatenin1 Generates Radial-like Hypercephalized Planarians. Development. 2008; 135, 1215-21. https://doi.org/ 10.1242/dev. 020289

36. Petersen CP, Reddien PW. Smed-betacatenin-1 is Required for Anteroposterior Oblastema Polarity in Planarian Regeneration. Science. 2008; 319, 327-30. https://doi.org/10.1126/science.1149943

37. Stückemann T, Cleland JP, Werner S, Thi-Kim Vu H, Bayersdorf R, Liu S-Y, Friedrich B, Jülicher F, Rink JC. Antagonistic selforganizing Patterning Systems Control Maintenance and Regeneration of the Anteroposterior Axis in Planarians. Dev Cell. 2017; 40, 248-63. e4. https://doi.org/10.1016/j.devcel.2016.12.024

38. Havens CG, Ho A, Yoshioka N, Dowdy SF. Regulation of Late G1/S Phase Transition and APC Cdh1 by Reactive Oxygen Species. Mol Cell Biol. 2006 Jun;26(12):4701-11. doi: 10.1128/MCB.00303-06. PMID: 16738333; PMCID: PMC1489138.

39. Behrend L, Henderson G, Zwacka RM. Reactive Oxygen Species in Oncogenic Transformation. Biochem Soc Trans. 2003 Dec;31 (Pt 6):1441-4. doi: 10.1042/bst0311441. PMID: 14641084.

40. Zhao H, Huang J, Li Y, Lv X, Zhou H, Wang H, Xu Y, Wang C, Wang J, Liu Z. ROS-scavenging Hydrogel to Promote Healing of Bacteria Infected Diabetic Wounds. Biomaterials. 2020 Nov;258:120286. doi: 10.1016/j.biomaterials.2020.120286. Epub 2020 Aug 5. PMID: 32798744.
41. Thi PL, Lee Y, Tran DL, Thi TTH, Kang JI, Park KM, Park KD. In situ Forming and Reactive Oxygen Species-scavenging Gelatin Hydrogels for Enhancing Wound Healing Efficacy. Acta Biomater. 2020 Feb;103:142-52. doi: 10.1016/j.actbio.2019.12.009. Epub 2019 Dec 14. PMID: 31846801.

42. Parham S, Kharazi AZ, Bakhsheshi-Rad HR, Nur H, Ismail AF, Sharif S, RamaKrishna S, Berto F. Antioxidant, Antimicrobial and Antiviral Properties of Herbal Materials. Antioxidants (Basel). 2020 Dec 21;9(12):1309. doi: 10.3390/antiox9121309. PMID: 33371338; PMCID: PMC7767362.

43. Song W, van Griensven, LJ. Pro- and Antioxidative Properties of Medicinal Mushroom Extracts. International Journal of Medicinal Mushrooms. 2008; 10(4), 315-324. https://doi.org/10.1615/IntJMed Mushr.v10.i4.30

44. Kozarski M, Klaus A, Nikšić M, (max of 6 authors), et al. Antioxidative Activities and Chemical Characterization of Polysaccharide Extracts from the Widely Used Mushrooms Ganoderma Applanatum, Ganoderma Lucidum, Lentinus Edodes and Trametes Versicolor Journal of Food Composition and Analysis: An Official Publication of the United Nations University, International Network of Food Data Systems. 2012;26(1-2):144-53. DOI: 10.1016/j.jfca.2012.02.004.

45. Devi S, Ghosh S, Das A, Borthhakur S, Singh I. Antioxidative and Free Radical Scavenging Activity of Ethanolic Extract of Lentinula Edodes. Asian J Pharm Clin Res. 2014 Jun 5;7(3):195-9.

46. Jaenen V, Fraguas S, Bijnens K, Heleven M, Artois T, Romero R, Smeets K, Cebrià F. Reactive Oxygen Species Rescue Regeneration after Silencing the MAPK-ERK Signaling Pathway in Schmidtea Mediterranea. Sci Rep. 2021 Jan 13;11(1):881. doi: 10.1038/s41598020-79588-1. PMID: 33441641; PMCID: PMC7806912.

47. Pirotte N, Stevens AS, Fraguas S, Plusquin M, Van Roten A, Van Belleghem F, Paesen R, Ameloot M, Cebrià F, Artois T, Smeets K. Reactive Oxygen Species in Planarian Regeneration: An Upstream Necessity for Correct Patterning and Brain Formation. Oxid Med Cell Longev. 2015;2015:392476. doi: 10.1155/2015/392476. Epub 2015 Jun 9. PMID: 26180588; PMCID: PMC4477255. 